M. Inal · Y. Yildirim • A. Incebiyik • M. Sanci •

C. Ispahi

\title{
Diagnostic accuracy of sonohysterography in the evaluation of uterine cavities in tamoxifen administered asymptomatic postmenopausal breast cancer patients with endometrial thickness $\geq 5 \mathrm{~mm}$
}

Received: 24 March 2006 / Accepted: 8 June 2006 / Published online: 7 September 2006

(C) Springer-Verlag Berlin / Heidelberg 2006

\begin{abstract}
To evaluate diagnostic efficacy of transvaginal saline infusion sonohysterography (TV-SHG) in the evaluation of uterine cavities in tamoxifen (TAM) administered asymptomatic postmenopausal breast cancer patients with increased endometrial thickness, sixty asymptomatic postmenopausal breast cancer women receiving adjuvant TAM treatment for at least 6 months and with endometrial thickness' $\geq 5 \mathrm{~mm}$ measured in transvaginal ultrasonography (TVS) were enrolled. Each patient underwent TV-SHG, followed by outpatient hysteroscopy (HYS) with endometrial biopsy. TV-SHG application was accepted as unsuccessful in four cases $(6.7 \%)$. When office HYS combined biopsy was considered as gold standard, the sensitivity, specificity, positive predictive value (PPV), and negative predictive value (NPV) of TV-SHG were estimated as $90 \%, 100 \%, 100 \%$, and $95 \%$, respectively. Our findings showed that TV-SHG was a valuable diagnostic tool in the evaluation of uterine cavities of TAM administered asymptomatic postmenopausal patients having an increased endometrial thickness.
\end{abstract}

Keywords Sonohysterography · Hysteroscopy · Endometrial thickness - Breast cancer · Tamoxifen

\section{Introduction}

Tamoxifen (TAM), a derivative of non-steroidal triphenylethylene, acts as selective estrogen modulators (SERM) by binding competitively with estrogen receptors in target organs including breast and women's genital tracts. Therefore, TAM has recently been widely used in breast cancer patients to lengthen the survival period and in

M. Inal $\cdot$ Y. Yildirim $(\bowtie) \cdot$ A. Incebiyik $\cdot$ M. Sanci $\cdot$ C. Ispahi Department of Gynecology, Aegean Obstetrics and Gynecology

Training and Research Hospital,

Yenisehir, Izmir, Turkey

e-mail: dr.yusufyildirim@yahoo.com.tr women under high risk for breast cancer as a prophylactic agent $[1,2]$. In addition, sometimes it is prescribed for ovulation induction and osteoporosis prevention in obstetrics and gynecology practice [3-5]. However, TAM has a partial agonistic effect on endometrium, which resembles estrogen treatment unopposed with progesterone $[6,7]$.

There is no consensus whether asymptomatic TAMtreated cases should be counseled any diagnostic intervention [8-12]. The American College of Obstetricians and Gynecologists (ACOG) recommendation for follow-up of asymptomatic women under TAM treatment includes annual pelvic examination and cervical PAP-smear [8]. Some authors have also recommended transvaginal ultrasonography (TVS) [13]. In spite of this, there is no established ultrasonographic endometrial cutoff value for the diagnosis of endometrial pathologies in asymptomatic postmenopausal TAM-treated patients, $5 \mathrm{~mm}$ is usually accepted as cutoff [14-17].

Previous studies noted that the best additional procedure was diagnostic office hysteroscopy (HYS) with high sensitivity and specificity. It was possible to diagnose intrauterine pathologies nearly $100 \%$ with a combination of HYS and biopsy as a diagnostic tool in cases of asymptomatic TAM-treated breast cancer [18-20]. In addition, transvaginal saline infusion sonohysterography (TV-SHG) has been studied to evaluate these patients [21]. However, this is one of the first studies of the evaluation of the diagnostic efficacy of TV-SHG in the evaluation of uterine cavities in TAM administered asymptomatic postmenopausal breast cancer patients with $\geq 5 \mathrm{~mm}$ of endometrial thickness measured by TVS.

\section{Materials and methods}

This study was performed at Aegean Obstetrics and Gynecology Training and Research Hospital, Department of Gynecology from November 2001 to October 2005. The Institutional Review Board (IRB) approved the study. Informed consent of all cases were taken in order to 
evaluate endometrium with TVS, TV-SHG, and office HYS.

The study was also conducted in accordance with the Helsinki Declaration of 1975 on human experimentation.

\section{Patients and selection criteria}

A total of 108 asymptomatic postmenopausal breast cancer patients receiving adjuvant TAM applied to our center for their routine controls in the study period. All of them underwent TVS and patients with an endometrial thickness $\geq 5 \mathrm{~mm}$ in TVS (Toshiba SSA-270A with $5 \mathrm{MHz}$ vaginal probe) were selected. All patients were postmenopausal and taking $20 \mathrm{mg} /$ day TAM for at least 6 months. None of patients were under estrogen replacement therapy. Additionally, cases with vaginal bleeding and/or previously treated because of gynecologic malignancies were excluded. Consequently, the final material of the study composed of 60 asymptomatic postmenopausal TAMtreated breast cancer patients with increased endometrial thickness.

\section{Interventions}

Prior to the procedures, general and gynecologic examinations of all of the cases were performed. After local cervical anesthesia by intracervical cathagel and analgesia with $100 \mathrm{mg}$ pethidine HCL, IV, cervical dilatation of cases was performed. Later, 5-F hysterosalphingography catheter with a $3 \mathrm{ml}$ latex balloon was placed in the uterine cavity and 5-20 ml of saline solution was infused into the cavity. TV-SHG signs were determined as normal (no intracavitary structural abnormality) and polypoid (intracavitary filling defect larger than $0.5 \mathrm{~cm}$ ) structure. Just after the completion of TV-SHG, subsequent office HYS was applied to all of the cases by the same physician who applied TV-SHG. The Microspon Hysteroscopy System was used for panoramic appearance. Distension of the uterine cavity was obtained using glycine solution $(400 \mathrm{ml} / \mathrm{min})$, and the intrauterine pressure, ranging from $175 \mathrm{~cm}$ to $275 \mathrm{~cm} \mathrm{H} 2 \mathrm{O}$, was automatically controlled by an electronic irrigation and suction device (Endomat, Karl Storz, Tuttlingen, Germany). An endoscopic camera was mounted to the telescopic end and the cavity was visualized with the monitor. The fundus, ostia, cornus, anteriorposterior and lateral walls and endocervical channel were inspected. During HYS, an endometrial biopsy was blindly performed. In patients with polypoid lesions, excision of the polyps was also performed. All of the biopsies were evaluated by the same pathologist.

\section{Statistical analysis}

All data of our study were analyzed by the pocket program of Statistical Program for Social Sciences, version 11.0 for Windows (SPSS Inc., Chicago, IL, USA). Based on the results of office HYS, the sensitivity, specificity, positive predictive value (PPV), and negative predictive value (NPV) of TV-SHG were estimated.

\section{Results}

Mean age of the patients was $56.61 \pm 7.2$ (range 44-65) years, mean body mass index $\left(\mathrm{kg} / \mathrm{m}^{2}\right)$ was $28.77 \pm 4.1$ (range 23-36), mean parity was $3.6 \pm 0.8$, mean period of menopause was $41.1 \pm 9.5$ (range 12-156) months, mean duration of TAM usage was $25.1 \pm 4.3$ (range $8-60$ ) months, mean period of breast cancer diagnosis was $39.6 \pm 11.8$ (range 14-96) months, and mean endometrial thickness was $7.8 \pm 2.9$ (range 5-24) $\mathrm{mm}$.

No intracavitary structural abnormality was found in 38 of the cases with TV-SHG. TV-SHG failed in four cases (no sufficient quality of vision was acquired). In all four cases, normal hysteroscopic appearance of endometrium was found during HYS. Table 1 shows sonohysterographic and hysteroscopic results of the patients. Overall, at the end of the studies in 20 cases $(33.3 \%)$ an intrauterine pathology was revealed (Table 2). One patient (1.7\%) was diagnosed with endometrial adenocarcinoma in situ, which was arising from an endometrial polyp.

According to these results, when HYS combined biopsy was accepted as gold standard, sensitivity, specificity, PPV, and NPV of TV-SHG were estimated as $90 \%, 100 \%, 100 \%$, and $95 \%$, respectively.

No complication was noted prior, during or after the procedures. All of the cases were discharged in 1 or 2 hours without any problem with oral antibiotic and analgesic.

\section{Discussion}

We found that approximately $33 \%$ of TAM-treated asymptomatic postmenopausal women with increased endometrial thickness had an intrauterine abnormality detected by TV-SHG or HYS. Furthermore, interventions allowed an early diagnosis of endometrial adenocarcinoma in-situ in one patient. Fong et al. have also reported that up to $40 \%$ of these asymptomatic patients has shown significant intrauterine pathology requiring further medical or surgical investigation and treatment, as well [12]. All these data have supported that TAM treated asymptomatic breast

Table 1 Sonohysterographic and hysteroscopic results of the patients

\begin{tabular}{lll}
\hline Results & $\begin{array}{l}\text { Transvaginal saline infusion } \\
\text { sonohysterography } N(\%)\end{array}$ & $\begin{array}{l}\text { Office diagnostic } \\
\text { hysteroscopy } N(\%)\end{array}$ \\
\hline $\begin{array}{l}\text { Normal } \\
\text { endometrium }\end{array}$ & $38(63.3 \%)$ & $40(66.7 \%)$ \\
$\begin{array}{l}\text { Polypoid } \\
\text { structure }\end{array}$ & $18(30 \%)$ & $20(33.3 \%)$ \\
$\begin{array}{l}\text { Failed } \\
\text { application }\end{array}$ & $4(6.7 \%)$ & - \\
\hline
\end{tabular}


Table 2 Histopathologic distribution of intrauterine (endometrial) pathologies

\begin{tabular}{lll}
\hline Results & $N$ & Percentage $\%$ \\
\hline Polyp & 10 & $50 \%$ \\
Simple hyperplasia & 6 & $30 \%$ \\
Atypical hyperplasia & 3 & $15 \%$ \\
Adeno-carcinoma in situ & 1 & $5 \%$ \\
\hline
\end{tabular}

cancer patients having an increased endometrial thickness measured by TVS need further evaluation of their uterine cavities.

Although TV-SHG is as effective as HYS at detecting and evaluating focally growing (polypoid) intrauterine lesions in both peri- and postmenopausal women with abnormal uterine bleeding [22-28], its role in the evaluation of uterine cavities' of asymptomatic TAMtreated postmenopausal cases with increased endometrial thickness is unclear. Many previous studies suggested that TV-SHG had high sensitivity and specificity rates ranging from $79 \%$ to $100 \%$ [29-32]. In contrast, some studies have reported a limited value for TV-SHG in detection of endometrial structural anomalies of TAM-treated postmenopausal cases $[33,34]$.

To our knowledge, in the last decade, only two studies resembling this current work have been published. Firstly, Garuti et al. compared feasibility, patient acceptance, and diagnostic accuracy of TV-SHG and HYS in 66 asymptomatic postmenopausal TAM-treated breast cancer women with an endometrial thickness of $\geq 5 \mathrm{~mm}$. All of their patients underwent TV-SHG, followed by outpatient HYS with endometrial biopsy. They suggested that sensitivity, specificity, NPV, and PPV of TV-SHG in distinguishing between normal and abnormal endometrium were approximately $86,83,94$, and $66 \%$, respectively, whereas HYS provided corresponding values of approximately 100 , 94, 98, and 100\%, respectively [29]. Secondly, Markovitch et al. performed TV-SHG followed by HYS and endometrial histological examinations to 85 TAM-treated asymptomatic breast cancer cases with increased endometrial thickness. They concluded that false-negative and falsepositive of TV-SHG were $2.4 \%$ and $8.2 \%$, respectively [35]. In our study, when HYS combined with histopathology was accepted gold standard, extremely high specificity, specificity, PPV, and NPV were found for TV-SHG.

Reported technical failed rate of TV-SHG ranges from $2 \%$ to $40 \%[29,36]$. Garuti et al.'s study revealed that no significant difference was found between TV-SHG and HYS in the subjective perception of pelvic discomfort. However, they could not apply TV-SHG to $39 \%$ of cases and HYS to $6 \%$ of cases because of cervical stenos or patient intolerance. They consequently concluded that HYS exposed the patients to the same pelvic discomfort as TV-SHG, but had a better feasibility rate [29]. Contrary to this, Rogerson et al. reported that TV-SHG had a high failure rate but had a lower pain score than HYS [37]. We had a $6.7 \%$ unsuccessful TV-SHG rate and no failed HYS application.
In conclusion, because a considerable rate of patients have an endometrial pathology $(33 \%$ for this current study), asymptomatic TAM treated women with increased endometrial thickness measured by conventional TVS should be evaluated as symptomatic women. In the assessment of these women, TV-SHG has an acceptable accuracy rate when compared with HYS which is the present gold standard for the study of endometrium.

\section{References}

1. Fisher B, Costantino JP, Wickerham DL, Redmond CK, Kavanah M, Cronin WM et al (1998) Tamoxifen for prevention of breast cancer: report of the National Surgical Adjuvant Breast and Bowel Project P-1 study. J Natl Cancer Inst 90:1371-1388

2. Early Breast Cancer Trialists' Collaborative Group (1998) Tamoxifen for early breast cancer. An overview of the randomized trials. Lancet 351:1451-1467

3. Beck J, Boothroyd C, Proctor M, Farquhar C, Hughes E (2005) Oral anti-estrogens and medical adjuncts for subfertility associated with anovulation. Cochrane Database Syst Rev $1: 2249$

4. Boostanfar R, Jain JK, Mishell DR Jr, Paulson RJ (2001) A prospective randomized trial comparing clomiphene citrate with tamoxifen citrate for ovulation induction. Fertil Steril 75: 1024-1026

5. Mackey JR, Joy AA (2005) Skeletal health in postmenopausal survivors of early breast cancer. Int J Cancer 114:1010-1015

6. Daniel Y, Inbar M, Peyser M (1996) The effects of tamoxifen treatment on the endometrium. Fertil Steril 6:65

7. Schmidt D (2006) Changes in the endometrium after tamoxifen therapy. Pathologe 27:27-32

8. American College of Obstetricians and Gynecologists (2000) Committee opinion, number 232. American College of Obstetricians and Gynecologists, April

9. Cohen I, Perel E, Flex D, Tepper R, Altaras MM, Cordoba M et al (1999) Endometrial pathology in postmenopausal tamoxifen treatment: comparison between gynaecologically symptomatic and asymptomatic breast cancer patients. J Clin Pathol 52: 278-282

10. Vosse M, Renard F, Coibion M, Neven P, Nogaret JM, Hertens D (2002) Endometrial disorders in 406 breast cancer patients on tamoxifen: the case for less intensive monitoring. Eur J Obstet Gynecol Reprod Biol 101:58-63

11. Ceci O, Bettocchi S, Marello F, Nappi L, Chiechi LM, Laricchia L et al (2000) Sonographic, hysteroscopic, and histologic evaluation of the endometrium in postmenopausal women with breast cancer receiving tamoxifen. J Am Assoc Gynecol Laparosc 7:77-81

12. Fong K, Kung R, Lytwyn A, Trudeau M, Chapman W, Nugent $P$ et al (2001) Endometrial evaluation with transvaginal US and hysterosonography in asymptomatic postmenopausal women with breast cancer receiving tamoxifen. Radiology 220: 765-773

13. LeDonne M, Lentini M, DeMeo L, Benedetto V, Misiti M (2005) Uterine pathologies in patients undergoing tamoxifen therapy for breast cancer: ultrasonographic, hysteroscopic and histological findings. Eur J Gynaecol Oncol 26:623-626

14. Omodei U, Ferrazzi E, Ramazzotto F, Becorpi A, Grimaldi E, Scarselli G et al (2004) Endometrial evaluation with transvaginal ultrasound during hormone therapy: a prospective multicenter study. Fertil Steril 81:1632-637

15. Smith-Bindman R, Weiss E, Feldstein V (2004) How thick is too thick? When endometrial thickness should prompt biopsy in postmenopausal women without vaginal bleeding. Ultrasound Obstet Gynecol 24:558-565 
16. Markovitch O, Tepper R, Fishman A, Shapira J, Aviram R, Cohen I (2004) The value of transvaginal ultrasonography in the prediction of endometrial pathologies in asymptomatic postmenopausal breast cancer tamoxifen-treated patients. Gynecol Oncol 95:456-462

17. Cohen I, Rosen D, Tepper R (1993) Ultrasonographic evaluation of the endometrium and correlation with endometrial sampling in postmenopausal patients treated with tamoxifen. J Ultrasound Med 5:275-280

18. Gebauer G, Hafner A, Siebzehnrubl E, Lang N (2001) Role of hysteroscopy in detection and extraction of endometrial polyps: results of a prospective study. Am J Obstet Gynecol 184:59-63

19. Garuti G, Grossi F, Cellani F, Centinaio G, Colonnelli M, Luerti M (2002) Hysteroscopic assessment of menopausal breastcancer patients taking tamoxifen; there is a bias from the mode of endometrial sampling in estimating endometrial morbidity? Breast Cancer Res Treat 72:245-253

20. Giorda G, Crivellari D, Veronesi A, Perin T, Campagnutta E, Carbone A et al (2002) Comparison of ultrasonography, hysteroscopy, and biopsy in the diagnosis of endometrial lesions in postmenopausal tamoxifen-treated patients. Acta Obstet Gynecol Scand 81:975-980

21. Tepper R, Beyth Y, Altaras MM, Zalel Y, Shapira J, Cordoba M, Cohen I (1997) Value of sonohysterography in asymptomatic postmenopausal tamoxifen-treated patients. Gynecol Oncol 64:386-391

22. Fukuda M, Shimizu T, Fukuda K, Yomura W, Shimizu S (1993) Transvaginal hysterosonography for differential diagnosis between submucous and intramural myoma. Gynecol Obstet Invest 35:236-239

23. Cicinelli E, Romano F, Anastasio PS, Blasi N, Parisi C (1994) Sonohysterography versus hysteroscopy in the diagnosis of endouterine polyps. Gynecol Obstet Invest 38:266-271

24. Widrich T, Bradley LD, Mitchinson AR, Collins RL (1996) Comparison of saline infusion sonography with office hysteroscopy for the evaluation of the endometrium. Am J Obstet Gynecol 174:1327-1334

25. Epstein E, Ramirez A, Skoog L, Valentin L (2001) Transvaginal sonography, saline contrast sonohysterography and hysteroscopy for the investigation of women with postmenopausal bleeding and endometrium $>5 \mathrm{~mm}$. Ultrasound Obstet Gynecol 18:157-162

26. Soares SR, Barbosa dos Reis MM, Camargos AF (2000) Diagnostic accuracy of sonohysterography, transvaginal sonography, and hysterosalpingography in patients with uterine cavity diseases. Fertil Steril 73:406-411
27. Bernard JP, Metzger U, Rizk E, Jeffry L, Camatte S, Taurelle R et al (2002) Hysterosonography. Gynecol Obstet Fertil 30: 882-889

28. Pasrija S, Trivedi SS, Narula MK (2004) Prospective study of saline infusion sonohysterography in evaluation of perimenopausal and postmenopausal women with abnormal uterine bleeding. J Obstet Gynaecol Res 30:27-33

29. Garuti G, Cellani F, Grossi F, Colonnelli M, Centinaio G, Luerti M (2002) Saline infusion sonography and tamoxifen intake. Gynecol Oncol 86:323-329

30. Valenzano M, Bertelli GF, Costantini S, Corticelli A, Mastro LD, Poeletti R et al (2001) Transvaginal ultrasonography and hysterosonography to monitor endometrial effects in tamoxifen-treated patients. Eur J Gynaecol Oncol 22:441-444

31. Timmerman D, Deprest J, Bourne T, Van den Berghe I, Collis WP, Vergote I (1998) A randomized trial on the use of ultrasonography or office hysteroscopy for endometrial assessment in postmenopausal patients with breast cancer who were treated with tamoxifen. Am J Obstet Gynecol 179:62-70

32. Hann LE, Gretz EM, Bach AM, Francis SM (2001) Sonohysterography for evaluation of the endometrium in women treated with tamoxifen. JR Am J Roentgenol $177: 337-342$

33. Berteli G, Valenzano M, Costantini S (2000) Limited value of sonohysterography for endometrial screening in asymptomatic postmenopausal patients treated with tamoxifen. Gynecol Oncol 78:275-277

34. Tamanaha S, Aldrighi JM, Santos RE, Prado RA (2004) Sensitivity and specificity of hysterosonography in endometrial abnormalities in asymptomatic postmenopausal women. Rev Assoc Med Bras 50:427-432

35. Markovitch O, Tepper R, Aviram R, Fishman A, Shapira J, Cohen I (2004) The value of sonohysterography in the prediction of endometrial pathologies in asymptomatic postmenopausal breast cancer tamoxifen-treated patients. Gynecol Oncol 94:754-759

36. Hann LE, Kim CM, Gonen M, Barakat R, Choi PH, Bach AM (2003) Sonohysterography compared with endometrial biopsy for evaluation of the endometrium in tamoxifen-treated women. J Ultrasound Med 22:1173-1179

37. Rogerson L, Bates J, Weston M, Duffy S (2002) A comparison of outpatient hysteroscopy with saline infusion hysterosonography. BJOG 109:800-804 